development of the cataracts, and more prolonged exposure to the small amounts of systemic steroids derived from inhalation and subsequent ingestion may have prevented resolution. It remains possible, however, that the inhaled steroids may alone have been responsible for the cataracts. Further studies are needed to confirm if patients with asthma taking regular inhaled steroids with and without occasional reducing doses of oral steroids have an increased risk of developing posterior subcapsular cataract. Until results of such studies are available patients should continue taking their inhaled steroids.

Hanburys, who market beclomethasone dipropionate as Becotide and Becloforte, have been informed about these adverse reactions.

1 Spaeth GL, Von Smallman L. Corticosteroids and cataracts. Int Ophthalmol Clin 1966;6:915-29.

2 Urban RC, Cotlier E. Corticosteroid induced cataracts. Surv Ophthalmol 1986;31:102-10.

3 Kewley GD. Possible association between beclomethasone dipropionate aerosol and cataracts. Aust Paediatr $\mathcal{F}$ 1980;16:117-8.

4 Rooklin AR, Lampert SI, Jaeger E, McGeady SJ, Mansmann HC. Posterior subcapsular cataracts in steroid-requiring asthmatic children. $\mathcal{F}$ Allergy Clin Immunol 1979;63:383-6.

5 Bigger JF, Palmberg PF, Becker B. Increased cellular sensitivity to glucocorticoids in primary open-angle glaucoma. Investigative Ophthalmology
$1972 ; 11: 832-7$.

(Accepted 10 May 1989,

\title{
General practitioners' use of electrocardiography: relevance to early thrombolytic treatment
}

M C Colquhoun

The Surgery, Malvern, Worcestershire WR14 3BL $M$ C Colquhoun, MRCP, general practitioner

Br.Med f 1989;299:433
Several recent trials have drawn attention to the benefits of thrombolytic treatment in acute myocardial infarction, ${ }^{1-3}$ and the evidence strongly suggests that the earlier these agents are given the greater the benefit. In the British Isles general practitioners are ideally placed to ensure the early use of these agents as they are often the first people to see the patient and delay in admission to hospital is still commonplace. Some trials of thrombolysis in hospitals have adopted electrocardiographic criteria to diagnose acute myocardial infarction' while others have relied on clinical data. ${ }^{2}$ The few studies in general practice have used electrocardiographic data. ${ }^{+}$The potential benefit of the widespread application of early thrombolysis" suggests a future role for general practitioners in initiating treatment. The side effects, however, make confirmation of the diagnosis important, and the only practicable test available to general practitioners is electrocardiography. Therefore an assessment of the availability and use of electrocardiography in managing acute myocardial infarction in general practice is important.

\section{Doctors, methods, and results}

I studied the Hereford and Worcester area, which is administered by one family practitioner committee and covers a large rural area, two cities, the outskirts of Birmingham, and several industrial towns. The standard of general practice is high with 660000 people on the lists of 348 general practitioners in 90 practices. The average list size (1900) is below the national average, and the use of deputising services is rare. All practices were sent a questionnaire recording the availability and use of electrocardiography in diagnosing acute myocardial infarction. Particular attention was paid to arrangements at different times of the day. Responses were obtained from $82(91 \%)$ of the practices, or $306(88 \%)$ of the area's doctors, an excellent response rate.

In total, $190(62 \%)$ doctors working in 44 practices had access to an electrocardiograph, 85 (45\%) of them recording an electrocardiogram in cases of suspected acute myocardial infarction during surgery hours and $50(26 \%)$ doing so outside normal working hours. When doctors who did not own an electrocardiograph were included $28 \%$ of doctors recorded electrocardiograms during surgery hours and $16 \%$ outside normal working hours. Only $25(13 \%)$ doctors routinely carried the machine with them outside normal working hours.

\section{Comment}

Although the majority of doctors had access to an electrocardiograph, fewer than half of them recorded electrocardiograms in patients suspected of having had an acute myocardial infarction; outside surgery hours the proportion was even smaller. Only $13 \%$ of the doctors routinely carried an electrocardiograph with them outside normal working hours - returning to the surgery to collect one might be considered to be unwise with the high incidence of early arrhythmias in acute myocardial infarction and the importance of early thrombolysis. My results suggest that (quite rightly) many general practitioners rely on the clinical picture for diagnosis and are aware of the misleading electrocardiograms that may be recorded during the early stages of infarction. If electrocardiographic confirmation of the diagnosis is considered to be essential before treatment with thrombolytic agents is started outside nospital my results suggest that the widespread introduction of these agents into general practice will be delayed.

Whether the use of thrombolytic agents in general practice before patients are admitted to hospital is justified is debatable because of a lack of data and the side effects of treatment. Furthermore, the patients most likely to benefit from thrombolytic treatment outside hospital are those with the longest journey to hospital, and the risks of transporting such patients have not been adequately studied. Whatever method is used to diagnose myocardial infarction outside hospital the overwhelming responsibility of general practitioners is to ensure that patients receive appropriate thrombolytic treatment as early as possible. Whether this treatment will become commonplace in general practice requires further study, but my results suggest that a considerable modification in general practitioners' use of electrocardiography will be necessary before it can become widespread.

I thank all the doctors who participated, Mr E E Penny and staff at Hereford and Worcester family practitioner committee for administrative help, and Professor D G Julian for his invaluable comments.

I Gruppo Italiano per lo Studio della Streptochinasi nell' Infarcto Miocardico GISSI). Effectiveness of intravenous thrombolytic treatment in acute myocardial infarction. Lancet 1986;1:397-402.

2 ASSET Study Group. Trial of tissue plasminogen activator for mortality reduction in acute myocardial infarction. Lancet 1988;ii: $525-30$

ISIS-2 (Second International Study of Infarct Survival) Collaborative Group. Randomised trial of intravenous streptokinase, oral aspirin, both, or neither among 17,187 cases of suspected myocardial infarction: ISIS-2. Lance 1988;ii:349-60.

Gordon I. Streptokinase used in general practice, $f R$ Coll Gen Pract 989:39:49-51.

5 Julian DG, Pentecost BL, Chamberlain DA. A milestone for myocardial infarction. Br Med f 1988;297:497-8.

Accepted 22 May 1989) 